\title{
EXPLORING THE EFFECTIVENESS OF SOCIAL MESSAGES ON PROMOTING ENERGY CONSERVATION BEHAVIOR IN BUILDINGS
}

\author{
SABA KHASHE ${ }^{\mathrm{a}}$, ARSALAN HEYDARIAN $^{\mathrm{b}}$, BURCIN BECERIK-GERBER $^{*}{ }^{\mathrm{c}}$, WENDY WOOD $^{\mathrm{d}}$ \\ ${ }^{a}$ University of Southern California, Viterbi School of Engineering, Sonny Astani Department of Civil and \\ Environmental Engineering, 3620 S. Vermont Avenue, Kaprielian Hall 210, Los Angeles, CA 90089- \\ 2531, Los Angeles, CA, USA, (e) skhashe@usc.edu \\ ${ }^{\mathrm{b}}$ University of Southern California, Viterbi School of Engineering, Sonny Astani Department of Civil and \\ Environmental Engineering, 3620 S. Vermont Avenue, Kaprielian Hall 210, Los Angeles, CA 90089- \\ 2531, Los Angeles, CA, USA, (e) heydaria@usc.edu
}

${ }^{c}$ University of Southern California, Viterbi School of Engineering, Sonny Astani Department of Civil and Environmental Engineering, 3620 S. Vermont Avenue, Kaprielian Hall 224C, Los Angeles, CA 900892531, Los Angeles, CA, USA, (t) +1 (213) 7404383 (f) +1 (213) 7441426 (e) becerik@usc.edu

${ }^{\mathrm{d}}$ Department of Psychology, Dana and David Dornsife College of Letters, Arts, and Sciences, University of Southern California, SGM 805, Los Angeles, CA, USA, (t) 1 (213) 7405504

(e) wendy.wood@usc.edu

* Corresponding Author

\section{Abstract}

Buildings could be transformed into interactive living spaces that communicate with their occupants and influence the way occupants behave in buildings. This paper focuses on investigating the effectiveness of incorporating social influence methods in the design of energy saving messages. Specifically, we examined the use of two classic compliance-gaining strategies that proved to have great influence on behavior in social psychology: foot-in-the-door and reciprocity and compared them to direct request. One hundred fifty participants were randomly assigned to one of the three experimental groups. Participants in three groups received text based messages that included the same simple energy saving tip. The only difference between the messages was the social influence methods used in framing the messages. Through the use of an immersive virtual environment, we observed the participants' compliance with the messages. Our analysis showed that reciprocity received significantly higher rates of compliance both in the virtual and physical environments. In addition, significant effects were found between the participants' personality traits and their compliance with the messages. We also found carryover effects between the behavior in the virtual part of the experiment and subsequent responses in the physical environment, suggesting participants acted in the same way in both environments.

Keywords: Energy conservation behavior; social influence method; immersive virtual environment; compliance; adherence; carry over effect

\section{INTRODUCTION}

40 Rapidly growing energy use is exhausting energy sources and resulting in energy cost increases and has

41 heavy environmental impacts, including ozone layer depletion, global warming, and climate change [1]. In

42 the U.S., residential and commercial buildings steadily increased their share in energy consumption, 43 reaching up to $41 \%$ of the total energy consumption in 2014 [2]. Based on the current trends, it is predicted 44 that between the years of 2013 and 2040, electricity consumption in commercial buildings will increase by 45 a higher rate (19\%) than other building types, including residential buildings (13\%) [3]. To reduce the 
increasing trend of energy consumption in buildings, technological and behavioral approaches have been adapted. Technological approaches focus on improving the energy efficiency of building systems. For example, the use of wireless sensor networks can enhance energy efficiency of heating, ventilating, and airconditioning (HVAC) systems [4]. Behavioral approaches focus on modifying occupant behavior. For example, providing feedback to occupants on their energy usage encourages them to further reduce their energy consumption [5]. Although technological improvements adapted in the design and operation of buildings can have an impressive influence on buildings' energy consumption, studies have shown that office buildings with sustainable technologies could consume more energy in comparison to conventional office buildings of the same function and size [6,7]. This underperformance is attributed to the differences in occupancy patterns and occupants' energy use characteristics $[8,9]$. Occupants and their behaviors are one of the most significant contributors to the building energy consumption [10,11]. How occupants interact with building energy and service systems and respond to environmental discomfort directly affect the operation of buildings and thus their building's energy use [12-14]. Therefore, savings gained through behavioral approaches are key to energy efficiency, leading to economic and environmental benefits and can result in energy savings in excess of 40 percent [15]. Energy efficient occupant behaviors provide higher savings with much lower costs than the investments made for technological approaches. In addition, behavioral approaches can be applied to both new and existing buildings [16].

Studies aimed to influence occupant behavior showed that motivating occupants towards the adaption of energy efficient behaviors -instead of energy wasting behavior - could result in energy savings from 5 to $30 \%$ [17-19]. Some of these energy efficient behaviors include adaption of day lighting instead of artificial lighting, natural ventilation instead of mechanical ventilation, choosing efficient temperature set-points [17], turning off office lights and HVAC during non-working hours [20,21], and clothing adjustments to accommodate more energy efficient set points [22,23]. Such findings reveal that occupants' actions and behaviors can significantly affect consumption and suggest that intervention strategies that promote sustainable behaviors could result in significant reductions of energy usage.

Change of lifestyle is a process of negotiation, communication, and interaction between occupants and their environment [24]. Communication interventions, which provide occupants with relevant information and motivation, may stimulate positive changes on occupants' energy consumption behavior and result in energy savings [25]. Research on communication strategies in the energy domain have not explored a number of social features that might increase energy conserving behavior in buildings. Social features represent the ways humans interact with each other. Social features include social influence strategies, such as making a direct request and other compliance gaining techniques that have proved to be successful in influencing behavior in marketing and psychology research [26-28]. In the present research, we adapt these social strategies to communications designed to promote energy conservation behavior. Specifically, we investigated whether building occupants would reduce energy consumption in response to energy saving messages adapting several classic social influence techniques. Energy consumption was tested in terms of lighting use, which is the building system influenced the most by user behavior and have significant impacts on electricity consumption [29-31].

The following sections of the paper provide a comprehensive literature review of communication intervention strategies in the energy domain and other domains, a presentation of the research objective and questions, and a description of the research methodology. An analysis of the data gathered through an Immersive Virtual Environment (IVE) system follows. Finally, a discussion of the results, conclusions, limitations of the work, and planned future work are presented.

\section{LITERATURE REVIEW}

Intervention strategies in the energy domain can be categorized into structural and informational strategies. Structural strategies have tried to influence behavior by changing contextual factors, such as price policies 
(e.g. energy tax). Informational strategies have often tried to influence behavior indirectly by changing people's attitudes, preferences, and other social judgments. Financial interventions are not as effective in commercial buildings because occupants in commercial buildings are usually not responsible for buildings' energy costs. We reviewed the previous work in the energy domain over a 50-year period and identified the following informational strategies: commitment (a pledge to behave in a specific way or achieve a certain goal) [32,33]; goal setting (setting a reference point of 5\% or 10\% energy savings for occupants) [34,35]; information (general knowledge about energy-related problems or various energy-saving measures occupants can adapt) [36,37]; feedback (providing occupants with information about their energy consumption or energy savings) [38,39]; gamification (the process of using games to engage users and solve problems) [40,41]; message framing (highlighting either the benefits of engaging in a particular behavior (a gain-frame) or the consequences of failing to engage in a particular behavior (a loss frame) [42]; modeling (presenting an appropriate model that performs a desired action) [43]; and providing an incentive or disincentive (strategies that motivate a range of pro-environmental behaviors) [44,45]. Instead of modifying behavior directly, these intervention strategies influence behavior by changing the underlying determinants, such as a person's values, attitudes, and self-efficacy (confidence in ability to perform a behavior) [46]. Furthermore, most of these interventions have been developed and tested for residential buildings, and they may be less relevant to commercial buildings, where occupants are not motivated to reduce power consumption because they do not pay energy bills.

114

115

116

117

118

119

120

121

122

123

124

125

126

127

128

129

130

131

132

133

134

135

136

137

138

139

140

141

142

143

144

145

146

Normative social influence, which is usually presented in terms of normative feedback, is another type of intervention strategy that has been proved to be effective in the energy domain $[47,48]$. Social influence norms pressure individuals to conform to desired behaviors [49], as a result of feelings of guilt about contributing to a social problem [50]. Normative social influence (e.g., "75\% of your neighbors reported to turn off the lights in unoccupied rooms") promote conservation behavior by motivating people to adapt conservation practices in order to conform to societal norms and align their behaviors with the typical behavior in their social context $[47,51]$. Normative social influence methods induce greater change in behavior compared to the interventions that highlight financial benefits, environmental protection, and social responsibilities [52]. In addition, Peschiera et al. [47] showed that behavior of a peer network could have greater impact on behavior of an occupant. They conducted a study of energy consumption behavior at a college dorm and found that the units exposed to comparative feedback, a comparison between individuals or groups about their energy consumption, saved more energy than the units that received feedback only about their own performance. The effects are even greater when more peers are involved in the feedback system. Although many studies reported success in reducing energy consumption by adaption of social norms based interventions [38,53,54], other studies reported undesired effects and challenges. Studies showed that peer comparison resulted in an increase in energy consumption for low consumers (lower than average peer consumption) [55,56]. The reason might be the decrease in the pressure and guilt about contributing to a social problem. Another challenge is having peers in the network with proenvironmental behavior [57,58]. Interventions to promote pro-environmental behaviors are needed before promoting this kind of behavior in social networks.

An alternative set of strategies has investigated tactics that directly change behavior. These strategies include compliance gaining techniques to promote desired behaviors (e.g., purchasing of goods and services) without social pressure [59]. Compliance tactics involve one individual attempting to induce another person to perform a desired behavior that the target person otherwise might not have performed [60]. According to Scott, compliance gaining techniques focus on modifying behavior directly rather than influencing the presumed cognitive determinants of behavior [61]. Different strategies are used to obtain compliance from users. Among the most common techniques used in the literature are foot-in-the-door and reciprocity techniques. In using the foot in the door (FITD) technique, the requester first makes a request so small that nearly anyone would comply. After the compliance with the first request occurs, a second, larger request is made - the one desired from the outset. People who comply to the initial, small request are more likely to then comply with the second request, compared with a control situation without a first request 
$[59,62]$. This technique is especially effective in social contexts, where initial attitudes may not be positive and gaining compliance to the larger request is difficult. Many studies investigated the effects of FITD on gaining compliance. For example, Freedman and Fraser [59] conducted two experiments investigating the influence of FITD technique on convincing housewives to allow a survey team of five or six men to come into their homes for 2 hours to classify their household products or to display a large ugly sign concerning safe driving in their front yard. These interactions involved phone contact, and the results showed that carrying out a small request increased the likelihood that the subjects would agree to a similar larger request. In another study, Gue'guen [63] carried out an experiment on fifty computer science students by sending an e-mail with a forty-question survey on their food habits, which required 15-20 minutes of their time. This questionnaire came from a hypothetical student at participants' own university. Half of the students had earlier responded to a small solicitation made by this same solicitor. Results showed that more compliance to the second request was obtained than in a control situation that did not involve the initial small solicitation. The results of similar studies showed that FITD technique increased compliance to the final request [64-66]. Studies also showed that FITD technique, which is a human - human communication technique, can be used in computer mediated communication settings $[63,67]$.

The norm of reciprocation obliges us to repay others for what we have received from them [68]. Reciprocation is a strong, pervasive social force in all human cultures and can be a powerful persuasive strategy [69]. In using this compliance-gaining tactic, the requester first does a favor and then asks something back. People reciprocate because they do not want to be judged as ungrateful for favors they receive [70]. Many studies have investigated the effects of reciprocity on gaining compliance. For example, Regan [71] conducted a laboratory experiment to examine the effect of a favor from a confederate on a compliance with a request. The results of his study showed that participants were more willing to purchase raffle tickets from a confederate if that confederate had earlier given them a soft drink as an unexpected favor. In another study, Whatley et al. [72] examined the influence of the social (public) and internal (private) consequences of reciprocation on behavior. In their study, participants were randomly assigned to conditions in which they were or were not given a small favor, and then were asked to comply with a request. In addition, participants expected that the person who asked for the favor would either know or not know whether they complied with the request. The results showed that, although, public compliance was greater than private compliance, the presence of a favor appeared to increase compliance in both public and private conditions. Research suggests that the rule of reciprocity in human-computer interactions can also influence users' behaviors [73-75]. For example, in creating a system to promote behavior change, Fogg and Nass [76] showed that it is possible to take advantage of the rule of reciprocity to motivate participants. In a web search task, participants were more likely to agree with, comply with, or help out a computer that had previously helped them. The influence of obligations to reciprocate has been shown in many other studies [77,78], highlighting the importance of reciprocation for increasing compliance. Our review of research on influence strategies to increase energy conservation did not identify any studies that evaluated these strategies, despite their promise for enhancing intervention effectiveness. However, we believe that these compliance gaining techniques potentially are transferable to the energy conservation context.

In addition, intervention strategies in the energy domain often use a one-size-fits-all approach in which they are not tailored to each individual user's characteristics. However, psychological factors, such as environmental attitudes and personality characteristics, importantly impact energy-related behaviors. Environmentally concerned occupants of a building tend to be more conservative in energy use [79]. Moreover, Shen et al showed that by incorporating personality traits into an energy-saving behavior analysis, they could generate a $15.5-20 \%$ greater reduction in building energy consumption [80]. In addition, suggesting the importance of considering occupant characteristics, people react differently to interventions based on their own personality traits (e.g., introvert vs. extravert) [81,82]. In light of these demonstrations of individual differences, the present study investigated how occupants' characteristics affected the ways compliance strategies influenced energy consumption. 


\section{RESEARCH METHODOLOGY}

The objective of this study is to investigate the effects of classic compliance gaining techniques involving foot in the door and reciprocity on promoting energy conservation behavior through influence appeals. The aim of these messages is to encourage building occupants to perform pro-environmental behaviors, in particular to use natural light instead of artificial light. Specifically, we aim to answer the following questions in this study:

- Do different social influence methods of foot in the door and reciprocity influence building occupants' compliance with energy saving messages?

- Do personality traits affect the occupants' compliance with the social messages?

\subsection{Immersive Virtual Environments and Carry Over Effect}

For our investigations, we simulated an office environment through an immersive virtual environment (IVE) technique. Many studies in different domains have utilized IVEs to simulate real-life settings [8387]. IVE tools offer several key methodological benefits to the researchers, including the ability to manipulate complex, abstract objects, and concepts while maintaining high experimental control and realism. In addition, IVEs allow researchers to control for potentially confounding variables that exist in built environments, such as time of day and various sky conditions, and isolate the variables of interest (i.e., influence of messages). Researches can easily and quickly change an environment's settings in IVEs (e.g., lighting settings, architectural and interior design settings, etc.) without any extra cost to investigate their influence on participants' behavior and cognition. This is a unique opportunity brought about by the use of IVEs as these kinds of modifications could be costly, time consuming and in some cases not feasible in real environments. IVEs also offer unique behavioral measurement opportunities [88]. Participants show more realistic behavior in the IVEs as they cannot see the experimenter so they do not feel like the experimenter is watching and/or judging them [89].

IVEs allow users to feel immersed within the virtual space as if they were in a physical space. Several studies have investigated if what participants learn, practice, and perform in the virtual world carry over into their real-world behaviors. For example, in one study, Ahn et al. [90] exposed participants to a virtual forest in which they were asked to cut a tree and then measured their subsequent pro-environmental behaviors. The results showed that the participants exposed to the virtual forest conserved paper by $25 \%$ compared with those who did not experience the virtual forest. In another study, Heydarian et al. [91] investigated whether IVEs could be adequate representations of physical environments. They measured user performance on a set of everyday office-related activities (e.g., reading text, identifying objects) and benchmarked the participants' performances in a similar real-world environment. The results showed that the participants performed similarly in an IVE setting as they did in the benchmarked environment for all of the measured tasks.

\subsection{Design of Experiment and Hypotheses}

We examined the effectiveness of two classic compliance-gaining strategies: (a) foot-in-the-door and (b) reciprocity $[92,93]$ and then compared them to (c) a direct request, in which participants were directly asked to engage in the desired behavior. The study included three experimental groups, which are shown in Table 1. The phrasing of these messages differed between groups, but they all included the same energy saving tip leading to energy conservation, i.e., opening the blinds for natural light and turning off artificial lights.

Table 1 - Messages delivered to participants in different groups

\begin{tabular}{ll}
\hline Social Influence Method & \multicolumn{1}{c}{ Message } \\
\hline Group 1: direct request & $\begin{array}{l}\text { "Could you please do me a favor and open the blinds and turn off the } \\
\text { artificial lights?" }\end{array}$ \\
\hline
\end{tabular}




\begin{tabular}{ll}
\hline Group 2: reciprocity & $\begin{array}{l}\text { "Could you please do me a favor and turn off the artificial lights if I } \\
\text { open the blinds for you?" }\end{array}$ \\
\hline Group 3: foot-in-the-door & $\begin{array}{l}\text { "Could you please do me a favor and open at least one of the blinds?" } \\
\text { and then "Could you please do me a favor and open the other blinds } \\
\text { and turn off the artificial lights?" }\end{array}$ \\
\hline
\end{tabular}

Participants were randomly assigned to one of the three groups. Based on the group that they were assigned, the participants were given the message through text and given an opportunity to comply with the message. We tested the following hypotheses by comparing the participants' compliance relating to their energy-use behaviors between these three groups:

H1a: Reciprocity technique engenders more compliance with the energy saving messages compared with the direct request.

H1b: FITD technique engenders more compliance with the energy saving messages compared with the direct request.

H2: Participants' personality traits will engender different patterns of compliance with the appeals.

We also examined possible carryover effects between the behavioral changes in the virtual part of the experiment and the real environment by testing the following hypothesis:

H3: Participants who complied or did not comply with the message in the virtual environment will act in the same way in the real environment.

\subsection{Experiment Setup}

To test these hypotheses, a virtual model of a single occupancy office was created in an IVE. The modeled office included the following features: light fixtures, three windows with blinds; a digital screen; a blackboard next to the screen, on which the messages would appear; a chair; and a conference table. An experiment was conducted over a period of three months (March 2015 through May 2015). Prior to running any experiments, the study was approved by the Institutional Review Board (IRB). First, a pilot study was conducted with 21 participants to ensure that the model, procedure, and the questionnaires were designed properly for the experiment. Based on the findings of the pilot study, we modified the model, as well as the questionnaires that were administered before and after the experiment, and conducted power analysis to determine the appropriate sample size. The results of the power analysis showed that 108 participants in total were needed to have close to 80 percent power to detect statistically significant effects in differences between the three conditions. We tested 50 participants for each condition ( $\mathrm{n}=150$ participants) resulting in 88 percent power. Participants were undergraduate and graduate students at the University of Southern California. They participated in the experiment voluntarily or received credit or incentives (i.e., pizza) for their participation.

\subsubsection{Pre-Experiment Session}

Prior to being immersed into the virtual environment, the participants were asked to complete a personality questionnaire assessing the Big Five Personality Traits [94] in order to investigate if personality affected reactions to the messages. The five personality traits included: extraversion (how social and assertive a person is); agreeableness (how cooperative and trusting, a person is); conscientiousness (how responsible and dependable, a person is); neuroticism (how anxious or prone to depression, a person is); and openness (how imaginative and intellectual, a person is).

After completing the pre-test survey, the participants underwent training to become more familiar with the virtual environment. They were instructed how to put on the head mounted display, adjust it to a comfortable state, and how to work with the different buttons on the controller. During the training, participants were immersed in the virtual environment and instructed with different tasks, such as moving 
around the room, turning on and off lights, and opening and closing blinds (Figure 1). These assigned tasks were similar to what the participants had to perform during the actual experiment. In addition, participants were asked to test different levels of lighting in the room. In this way, they could experience how much light would be in the room if they choose to open the blinds or turn on the lights. In addition, participants could see that there was no specific view behind the windows (it was just the blue sky). Thus, any desire to see the view did not affect the results.


Figure 1- A participant during training

After the training, participants heard the following explanation: "You will be immersed in an office room and you will be asked to sit on a chair and watch a video, which is a TED talk. Please watch the video very carefully. You will be asked to answer questions about the video after the experiment. You have the option to pause or resume the video whenever you want. During the experiment, the building might communicate with you through the blackboard across from you and request a favor. Please read the request carefully. You will be asked what the request was at the end of the experiment. However, it is completely up to you whether or not to comply with the request. Please try to act exactly as you would if you were in your office. Please let us know if you experience any motion sickness so we can stop the experiment immediately."

\subsubsection{Experiment Session}

After the pre-experiment session, the participants were asked to put on the head mounted display so that they could be immersed in the virtual environment. In the virtual office, the default lighting setting was all the lights on and all the blinds closed (Figure 2a). Through real-time rendering, four other lighting settings were created: (1) a bright room with all light bulbs on while one of the blinds (left blind) was open and the other two were closed (Figure 2b); (2) a bright room with all light bulbs on while one of the blinds (middle blind) was open and the other two were closed (Figure 2c); (3) a bright room with all light bulbs on while one of the blinds (right blind) was open and the other two were closed (Figure 2d); and (4) a bright room with all light bulbs off while all the blinds were open (Figure 2e). Lighting distributions (lux) for all the possible lighting conditions in the model were according to the standards for interior office spaces, ranging from 885 to 1100 lux. 


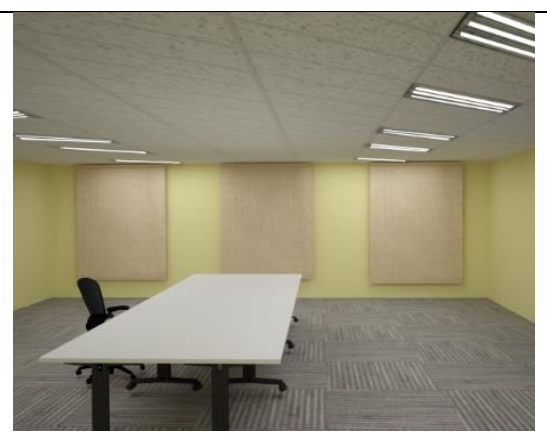

(a)

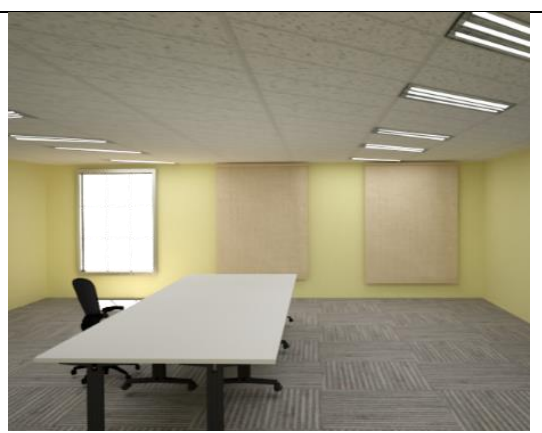

(b)

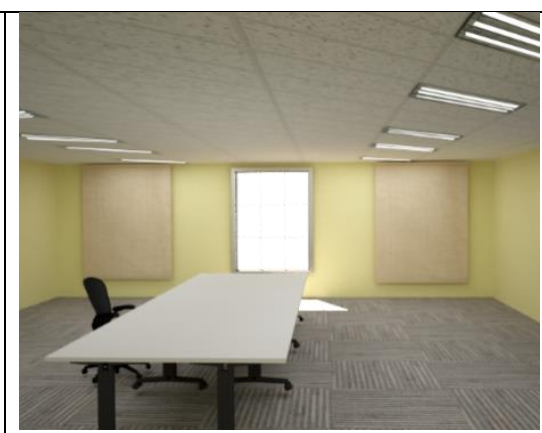

(c)

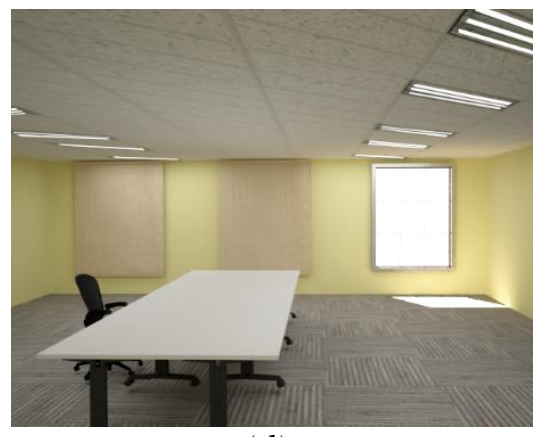

(d)



(e)

Figure 2 - Different lighting levels in the room: (a) all light bulbs on and all blinds closed; $(b)$ all light bulbs on and the left blind open; (c) all light bulbs on and the middle blind open; (d) all light bulbs on and the right blind open; (e) all light bulbs off and all the blinds open

Participants entered the virtual room, sat on the chair, and watched a video for 4 minutes and 43 seconds on the digital screen (Figure 3a). While participants were watching the video at the $90^{\text {th }}$ second, they were given a message in text, which was shown on the blackboard next to the digital screen and accompanied by a beeping sound (Figure $3 \mathrm{~b}$ ). Participants were exposed to different messages according to their assigned experimental condition and were given an opportunity to interact with the environmental room (e.g., adjusting lighting by opening the blinds and turning off the lights). In group 1, participants were asked to turn off the lights and open all of the blinds. In group 2, the participants were asked to turn off the artificial lights (the building had already opened the blinds for them, in order to establish reciprocity). In group 3 , the participants were first asked to open one of the blinds and if they complied, then they were asked to open the other blinds and turn off the artificial lights. We assessed whether participants complied with the buildings' requests about energy conservation behavior. All of the participants had the ability to pause the video, comply with the message, and continue watching the video. All experiments were conducted on sunny and non-cloudy days between $10 \mathrm{AM}$ and 4 PM Los Angeles time to make sure that there were no effects due to variations in lighting levels in the physical and virtual environment at the times that the experiment was conducted. For example, if the experiment was conducted at night when the sky was dark or when the outside weather was gloomy or rainy, participants might have an unconscious intuition that if the blinds were to be open in the virtual space, they would not be able to get enough natural light (regardless of how the IVE is designed). 




(a)

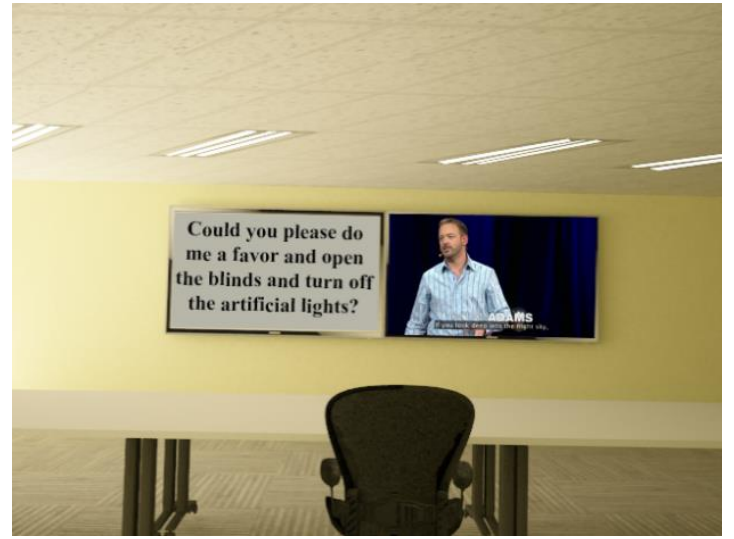

(b)


Figure 3- How message was delivered to the participants in the immersive virtual environment: (a) a participant watching a video in the immersive virtual environment; (b) Message delivered to the participant while watching the video

\subsubsection{Carry Over Effect}

When participants completed watching the video in the virtual environment, they were asked to remove the head mounted display. Then they went to a physical office room to take the post-test survey. The lighting conditions in the physical office room were the same as in the virtual office room (all artificial lights on/ blind closed). As the participants were completing the survey, the computer screen next to them displayed the same text messages that were delivered to them in the virtual environment in groups 1,2 , or 3 , accompanied by the same beeping sound. We observed participants' compliance/noncompliance in the physical office room to determine if their behavior in the virtual environment carried over to the real environment (Figure 4).

Figure 4 - How message was delivered to the participants in the physical office environment: (a) a participant completing surveys in the physical office; (b) message delivered to the participant while completing the survey 


\subsubsection{Post-Surveys}

In the post-experiment session, participants filled out post-surveys. The post-surveys were composed of four parts: (1) questionnaire about participants' age, gender, degree objective, and major, etc.; (2) an IVE interaction questionnaire assessing perceptions of the virtual environment (realism); (3) a survey to assess participants' intentions to use a similar system, if it were employed in their building, investigate the reasons behind their decisions, and solicit suggestions for potential improvement; and (4) a questionnaire to assess participants' environmental values (environmental concerns and daily environmental habits, such as turning personal electronics off when not in use, etc.) and views (attitudes about recycling and usage of eco-friendly products) adapted from Ishaswini et al. [95] measuring general environmental concerns and knowledge of environmental issues. They were modified to assess factors related to building occupants' behaviors rather than consumers' buying behaviors. After filling out the post surveys, the participants were thanked and dismissed.

\subsection{Modeling}

The model of the single occupancy office space was first generated in Revit@ 2015 and then taken to 3ds Max@ to optimize the geometry and add materials, furniture, texture, lighting, reflection, and shadows in order to make it look more photo realistic. Once all the necessary components to make the room look realistic were added in $3 \mathrm{ds}$ Max $\odot$, different renderings (render-to-texture) were created for every lighting combination that we needed to have in our scenarios. Lighting distributions (lux) for all the possible lighting conditions in the model were set according to the standards for interior office spaces, and the lux values approximately ranged from 300 to 1100 lux. The model was designed to reflect the natural light level for a sunny Los Angeles day at 2:00 PM, so that all of the participants experienced the same level of natural light during the experiment. The rendered models were imported in the Unity@ game engine as different scenes. The Unity $\odot$ game engine was used to program interactive options, such as opening/closing blind animations, turning on/off lights animations, and the ability to play/pause/resume videos in a way that would allow the participants to have more realistic interactions with the virtual interactive model. For example, the participants were able to turn lights on/off by standing in front of the light switch, open/close the blind by standing in front of a window or pause/resume videos using a controller. We used Oculus DK2 Head-Mounted Display (HMD) to provide a fully immersive environment that included an Xbox-360 controller and a positional tracker that would track the participants' head and neck movements.

\subsection{Data Analysis}

We tested the research hypotheses by performing statistical analysis on the data collected from the participants in the three groups. Chi-squared goodness of fit test $\left(\chi^{2}\right)$, McNemar Chi-square test $\left(\chi^{2}\right)$, ANOVA, t-test, and ordinary least square (OLS) linear regression were used to analyze the data. The results of chi-squared goodness of fit test and McNemar Chi-square test were reported with degrees of freedom and sample size in parentheses, the Pearson chi-square value $\left(\chi^{2}\right)$ and the significance level $(p),\left(\chi^{2}(\mathrm{df}, \mathrm{N})\right.$ $, p)$. The results of ANOVA are reported by between-groups degrees of freedom and the within-groups degrees of freedom as well as the $F$ statistics and the significance level $(p),(F(\mathrm{df}), p)$. The results of $t$-test were reported by $t$ statistics and the significance level $(p),(t(\mathrm{df}), p)$. Ordinary least square (OLS) linear regression output was reported with unstandardized slope $(\beta)$, with the $t$-test $(t)$ and the corresponding significance level $(p),(\beta, t(N-k-1), p), k$ equals the number of predictor variables [96]. The analyses are based on alpha $(\alpha)$ equals to 0.05 . In order to interpret the results, $p$-values $(p)$ are provided below and the null hypotheses $\left(\mathrm{H}_{0}\right)$ are rejected when $p \leq$ alpha. The results are also considered as marginally significant when the $p$ value is larger than 0.05 and smaller than $0.1(0.05<p<0.1)$. 


\section{RESULTS AND DISCUSSION}

The results presented in this paper are based on 150 participants (89 males and 61 females). Participants were distributed equally between the groups (50 participants in each group). Participants were undergraduate and graduate students at the University of Southern California enrolled in different majors including: engineering (55\%); psychology (26\%); and other majors (19\%) including business, cinematic arts, communication, preventive medicine, etc. The majority of the participants were 18 to 29 years old $(91 \%)$ and the rest were around 30 to 39 years old $(9 \%)$.

Using the IVE as a tool to collect data, one of our main concerns was whether the virtual environment was an adequate representation of the physical environment. Therefore, we evaluated the participants' sense of the realism of the environment through the IVE interaction questionnaire. The results showed that participants rated the realism of the environment to be realistic on average $(\mathrm{M}=3.79, \mathrm{SD}=0.69)$ based on a five-point Likert scale (1-very unrealistic, 2- unrealistic, 3 - neutral, 4- realistic, and 5-very realistic). The majority of participants $(81 \%)$ rated the virtual environment as realistic, $12 \%$ rated it to be neutral, and the rest $(7 \%)$ believed that it was unrealistic.

In order to test $\mathrm{H} 1 \mathrm{a}$ and $\mathrm{H} 1 \mathrm{~b}$, which suggested that the use of reciprocity or FITD engenders more compliance than the direct request, we compared the participants' compliance with the energy saving messages in the three experimental groups: (1) direct request; (2) reciprocity; and (3) foot-in- the-door. Our analysis showed that reciprocity generated a significantly higher rate of compliance (82\%), followed by the direct request (62\%), and FITD (50\%). Statistical analysis, using a chi-squared goodness of fit test, suggested accepting H1a, given that the percentage of participants who complied with reciprocal requests was significantly greater than the percentage of participants who complied with direct requests $\left(\chi^{2}(1, N=\right.$ $100)=4.96, p=0.026<0.05)$. Table 3 shows details of the analysis. In addition, the percentage of participants who complied with FITD was not significantly different than the percentage participants who complied with a direct request $\left(\chi^{2}(1, N=100)=1.461, p=0.23>0.05\right)$, rejecting H1b.

Table 3 - Direct request vs. reciprocal requests vs. FITD in virtual environment ( $\chi^{2}$ analysis compliance vs. non-compliance)

\begin{tabular}{lccc}
\hline & \multicolumn{1}{c}{ Compliance } & Non-compliance & Total \\
\hline Direct request & $31(32.33) \chi^{2}=[0.05]$ & $19(17.67) \chi^{2}=[0.10]$ & 50 \\
\hline Rule of reciprocity & $41(32.33) \chi^{2}=[2.32]$ & $9(17.67) \chi^{2}=[4.25]$ & 50 \\
\hline FITD & $25(32.33) \chi^{2}=[1.66]$ & $25(17.67) \chi^{2}=[3.04]$ & 50 \\
\hline Total & 97 & 53 & 150 \\
\hline
\end{tabular}

We also examined the effects of the participants' personality and environmental values and views on their compliance with the energy saving messages. We first checked the collected data to make sure that participants were distributed evenly in the three experimental groups and found no significant difference between the three experimental groups. Analyses investigating how individuals' environmental values and views are related to compliance revealed no significant effects between environmental values views and their compliance. We tested the relation between personality traits and the experiment results by using simple linear and logistic regression analyses (personality traits predicting the dependent variable, compliance vs. non-compliance). Participants' level of openness (which refers to the degree to which participants were open to new experiences/new ways of doing things) and neuroticism (which refers to degree to which participants were anxious or impervious to what's going on around them) influenced their compliance with the message. In general, participants with higher levels of openness were more likely to comply with the messages $(\beta=1.047, \mathrm{t}(148)=2.745, p=0.007<0.05)$. In addition, participants with higher levels of neuroticism were (marginally) more likely to not comply with the messages $(\beta=-0.664$ $\mathrm{t}(148)=-1.686, p=0.094<0.1)$. These results are consistent with the findings in the health care domain 
suggesting that high neuroticism is significantly associated with non-compliance [101-103] and that openness to experience is positively associated with compliance [104]. In addition, studies conducted by Milfont and Selby investigating how personality traits are associated with environmental engagement showed that environmental values and engagements are associated with openness and lower neuroticism [105].

Given that participants' personality traits influenced their compliance with the messages, we investigated if these personality traits would influence the effects of different social influence tactics. To do this, we ran separate regression analyses using personality traits as predictors of participants' compliance with the message in the three experimental groups. The results revealed that participants with higher levels of neuroticism were more likely to not comply with the direct request $(\beta=-1.776, \mathrm{t}(98)=-2.285, p=0.027<$ 0.05 ). This could reflect that highly neurotic individuals experience a wide range of negative emotions [106], leading to non-compliance. Use of compliance-gaining techniques might mediate these effects, as results show no association between neuroticism and non-compliance in the two other experimental groups. Our analysis also showed significant relations between participants' level of openness and their compliance with the message involving reciprocity $(\beta=1.736, \mathrm{t}(98)=3.303, p=0.002<0.05)$. Individuals who scored higher in openness, who are tolerant of new experiences and ideas and have active imagination, might become more engaged with a system in which buildings are communicating with them and do a favor and ask something in return. These results confirm H2, suggesting participants' personality traits would influence participants' compliance with the social messages.

Participants were also asked to identify the reasons behind their compliance or non-compliance with the message. Conducting the chi-square test of independence, the results showed no significant differences between participants' reasons to comply or not comply with the request among the three experimental groups. The majority of participants in all of the groups indicated that they complied because they did not feel like saying no. They also stated other reasons, mostly referring to simplicity of the favor that they did not mind doing or having no particular preference in terms of lighting. In addition, the main reasons for non-compliance were preference for artificial light, not liking the way that the request was made, and consideration of the favor as an extra effort. Although the majority of participants in the direct request and FITD groups ( $26 \%$ of the participants who did not comply in the direct request and $28 \%$ of the participants who did not comply in FITD) mentioned not liking the way that request was provided as the reason for their non-compliance, none of the participants in the reciprocity condition mentioned this as a reason for noncompliance. In addition, a large portion of participants in the direct request group and the FITD group (36\% of the participants who did not comply in the direct request and $32 \%$ of the participants who did not comply in FITD) stated that the reason for their non-compliance was that the request was an extra effort. However, fewer participants in the reciprocal requests group 2 (20\% who did not comply in group 2) considered the request an extra effort. Other reasons for noncompliance mentioned by the participants were mostly related to their desire to focus on the video and not liking interruptions or multitasking.

Investigating the participants' compliance in the physical environment, collecting data from 45 participants out of 50 participants in each group, our analysis showed that reciprocity generated a significantly higher rate of compliance (73\%), followed by the direct request (56\%), and FITD (47\%). Statistical analysis, using a chi-squared goodness of fit test showed that the percentage of participants who complied with reciprocal requests was significantly greater than the percentage of participants who complied with direct requests $\left(\chi^{2}\right.$ $(1, N=90)=0.86, p=0.035<0.05)$ and with FITD $\left(\chi^{2}(1, N=90)=4.85, p=0.028<0.05\right)$. In addition, the percentage of participants who complied with a direct request was not significantly different than the percentage participants who complied with $\operatorname{FITD}\left(\chi^{2}(1, N=90)=1.67, p=0.19>0.05\right)$. We also examined the possible carryover effects by which behavioral changes in the virtual part of the experiment were transferred to the real environment. Using McNemar's test for paired nominal data, no significant differences in individuals' compliance emerged between the virtual room and physical room in general $\left(\chi^{2}\right.$ 
$(1, N=135)=80.011, p=0.118>0.05)$. Thus, participants, who complied or did not comply with the messages in the virtual environment acted in the same way in real life. This suggests accepting $\mathrm{H}_{3}$, in which virtual environments provide an excellent venue for testing real-world behavior change interventions.

We also asked the participants to rate their intentions to use a similar suggestion system, if it were employed in their buildings in the future. The results are presented in Figure 5. We wanted to understand how similar systems could be employed in the design of future buildings and operation of existing buildings. Using ANOVA, the results showed that there were significant differences between the participants who complied with the request and who did not comply $(F(1,148)=8.635, p=0.004<0.05)$. Participants, who complied with the requests, were more likely to use a similar suggestion system than participants, who did not comply with the requests. Participants, who did not comply, were more neutral about using the suggestion system. Most of the participants, who did not comply with the request, said that they were likely to use a similar suggestion system, mentioned being an extra effort and interruption as the reasons for not complying with the request. Taking advantage of automation (which we implied indirectly to some extend in group 2) could decrease the level of the effort and increase the compliance. The participants also suggested some modifications to the system, such as using another modality like voice to deliver the messages. Thus, there are potential ways to improve the suggestion system to motivate those who did not comply with the messages.

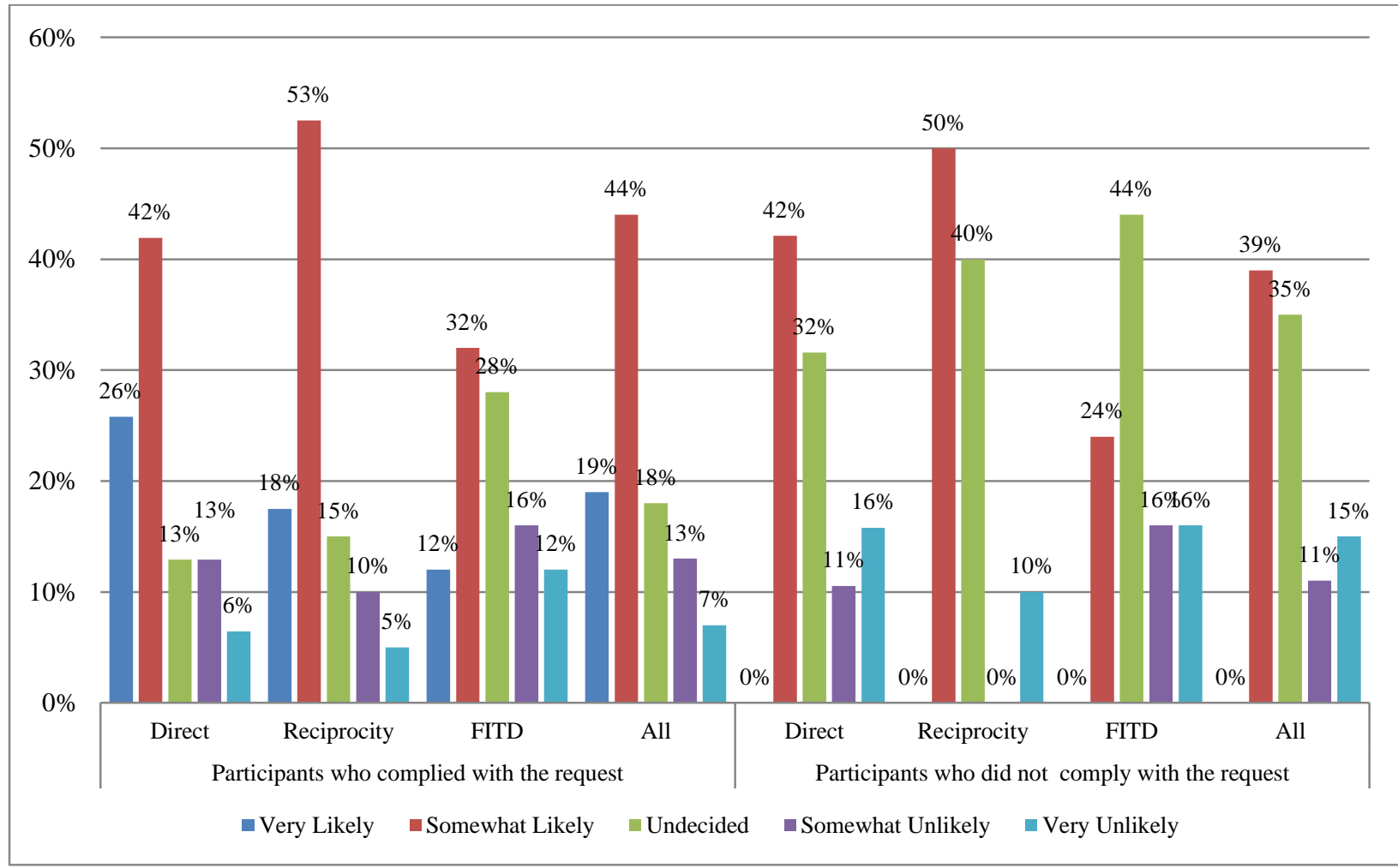

Figure 5 - Participants' intentions to use a similar suggestion system if it was employed in their building in the future

In addition, the participants were asked if they felt that they would have responded in a similar fashion to the buildings' request if it were employed in their own office. The results are presented in Figure 6. Sixtytwo percent of the participants said that they would respond in similar fashion, $13 \%$ said that they would not respond in similar way and $25 \%$ were neutral. The results showed a significant difference between participants who complied with the request and those who did not comply in terms of their tendency to respond in the similar fashion $(F(1,148)=5.466, p=0.021<0.05)$. Participants, who complied with the 
requests, were more likely to behave in a similar fashion in their own office compared with participants, who did not comply with the requests. The results showed that a significant number of the participants, who did not comply with the request, were unsure if they would behave in a similar fashion, and they provided comments stating that they would comply with the request if there were changes in the suggestion system. For example, they might comply if an authority, such as their boss were asking for the request or if the request were delivered through voice instead of text.

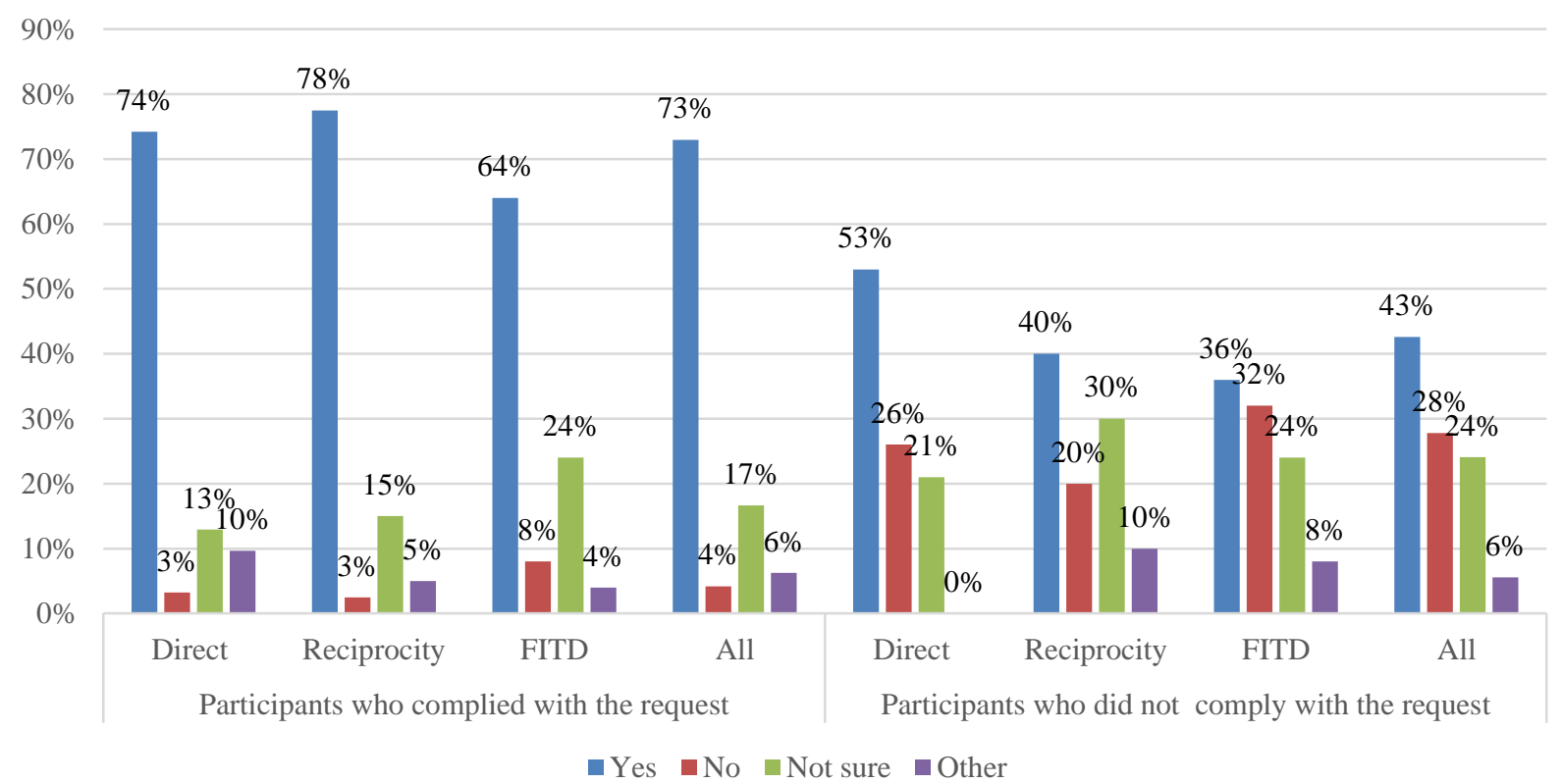

\section{Figure 6 - Participants intentions to respond in a similar fashion to the buildings' request if it was} employed in their own office

We also asked participants if there was anything about the system that they would like to change. Their suggested changes included adaption of different delivery styles rather than text, such as through voice or by virtual person, as well as adaption of different delivery methods rather than a screen on the wall, such as email or mobile applications. In addition, participants believed that the suggestion system should take office activities into account to find the best timing for the message. Participants believed that having another character provide the request to the user might enhance the effectiveness of the message. Another suggestion included personalization of the system to the user. For example, participants thought that the message could be more influential if it took user's age, gender, and position into consideration.

In this study, we examined the influence of two classic compliance gaining techniques, foot-in-the-door and reciprocity, which are used in human communications to gain adherence on desired behaviors. Previous studies in different domains reported that these two techniques increase compliance with a request $[64,65,71,72]$. Although the results of the present study showed no significant difference between the participants' compliance with direct request and FTD, reciprocity significantly increased compliance with the energy saving messages. What differentiated our study from previous work done in the energy domain was that we focused on communication intervention strategies, applying social influence methods rather than providing feedback or information by visualizing energy data (charts directly representing an individual's energy use [97,98] or as indirect interventions e.g., ambient light providing feedback by changing color depending on energy consumption [99] or virtual object, such as a digital pet with dynamically changing state associated with energy consumption [100]). In addition, we adapted compliance gaining techniques, which attempt to influence behavior without social pressure, compared to influence that use social norms. 


\section{LIMITATIONS AND FUTURE RESEARCH}

We used a novel data collection approach, which provided us with the ability to focus on the variable of interest (i.e., the effect of two compliance gaining methods) and eliminated the influence of potential confounding variables, such as sky conditions or time of day, which could have affected the lighting levels. Although IVEs allow us to create and provide realistic settings, there still exists a number of limitations that come with such technologies. For example, participants had to use a controller to navigate in the virtual environment instead of walking around, which changes the amount of effort needed to complete a task. However, according to the participants' responses on the realism of the IVE, as well as, our experience in our previous studies where we used IVE for investigating the effects of design factors in an office environment, we believe the limitations of IVE were not significant enough to have an influence on the participants' interactions within the virtual office space. However, there are other limitations. For example, in real-life experimental settings, we can collect and analyze the end-user behavioral information throughout a day or a longer period of time, yet due to motion sickness, we cannot keep participants longer than 30 to 60 minutes within virtual environments. Although, our focus in this paper was to investigate the effectiveness of incorporating social influence methods in the design of energy saving messages, our findings are based on the initial influence of such messages on end-users, regardless of the influence of such methods over a period of time. In our future studies, we plan to use our findings in this study and conduct field experiments to better understand the effect of such influences on the occupants over a longer period of time. In addition, similar to the other methods (e.g., observations, field studies) used in collecting occupant behavior, there exists a limitation with our methodology, which is participants might not behave exactly the same way as they would when they are not observed. The way to address this issue is, again, to conduct longer studies, which is a gap in literature. In this study, the participants were students, who were highly educated and mostly around 18-29 years old. Therefore, the results might not be generalized to the entire population. We plan to conduct experiments with larger sample sizes with more diversity in terms of different characteristics to fully investigate the correlation of these factors with effects of social influence methods and be able to generalize the results to a larger population. This study is a part of broader study that aims to transform buildings into interactive living spaces that communicate with their occupants and influence the way occupants behave in buildings. In this study, we focused on the effectiveness of social influence methods in framing of the energy saving messages. In our future studies, we will examine the other factors that might enhance the human-building communication, such as the effectiveness of different modalities (e.g., text, voice) to deliver pro-environmental messages. We will test and validate the findings of these studies by implementing similar suggestion systems in real office spaces with actual occupants and measure the changes in actual energy consumption during a specific period of time. The messages framed with different social influence methods will be delivered through text or voice on the monitor screen while participants are performing office related activities. Occupants' behaviors would be observed and the energy consumption of the office space would be measured to identify the effectiveness of proenvironmental messages on occupants' energy related behaviors.

\section{CONCLUSIONS}

In this study, we investigated the influence of social influence techniques that are used in human communication to gain adherence on building occupants' energy related behaviors. Specifically, we examined the use of classic compliance-gaining strategies: foot-in-the-door and reciprocity. We compared these to direct requests. We also investigated whether the results obtained through IVE could be transferred to the real environments. Our analysis showed that reciprocity received a significantly higher rate of compliance (82\%), followed by direct request (62\%), and FITD (50\%) in the virtual environment. Similarly, reciprocity received significantly higher compliance $(73 \%)$ in the real environment, followed by direct request $(56 \%)$ and FITD (47\%). Investigating how different user personality traits could impact response to building requests, we found that reciprocity induced greater compliance among participants with higher rate of openness. In addition, participants with higher rates of neuroticism were less likely to comply with direct requests. Suggesting the usefulness of IVE to evaluate compliance, there were no significant 
618

619

620

621

622

623

624

625

626

627

628

629

630

631

632

633

634

635

636

637

638

639

640

641

642

643

644

645

646

647

648

649

650

651

652

653

654

differences in participants' compliance in the virtual room vs. physical room in the three experimental groups. In addition, there were no significant differences between the participants' preference of using a similar suggestion system in their own office or their intentions to respond in similar way in the real world in the three experimental groups. The results also suggested that there are potentials to increase the compliance by changing some aspects of the suggestion system, such as its delivery style or source characteristics. However, we were not able to detect any significant effects in terms of participants' age, income levels, or environmental view and values. This is due to the fact that our participants were mostly college students, a limitation of our study, which we plan to address in our future studies.

\section{Acknowledgements}

This material is based upon work supported by the National Science Foundation under Grant No. 1351701. Any opinions, findings, and conclusions or recommendations expressed in this material are those of the authors and do not necessarily reflect the views of the National Science Foundation. Special thanks also to all of the participants and the researchers that contributed to this study, specifically to Joao Carneiro for his contributions in modeling.

\section{REFERENCES}

[1] Pérez-Lombard, L., Ortiz, J., Pout, C., A review on buildings energy consumption information, Energy and Buildings. 2008, 40(3), 394-398.

[2] U.S. Energy Information Administration, eia. How much energy is consumed in residential and commercial buildings in the United States? Last updated April 2015, Last accessed November 2015, Available at: http://www.eia.gov/tools/faqs/faq.cfm?id=86\&t=1.

[3] U.S. Energy Information Administration, eia. Energy Information Administration's Annual Energy Outlook, Last updated April 2015, Last accessed November 2015, Available at: http://www.eia.gov/forecasts/aeo/er/excel/aeotab_2.xlsx.

[4] Guo, W., Zhou, M. Technologies toward thermal comfort-based and energy-efficient HVAC systems: A review, Systems, Man and Cybernetics, 2009. IEEE International Conference. 2009, 3883-3888.

[5] Chen, H., Lin, C., Hsieh, S., Chao, H., Chen, C., Shiu, R., Ye, S., Deng, Y. Persuasive feedback model for inducing energy conservation behaviors of building users based on interaction with a virtual object. Energy and Buildings. 2012, 45, 106-115.

[6] Sawyer, L., De Wilde, P., Turpin-Brooks, S. Energy performance and occupancy satisfaction: A comparison of two closely related buildings. Facilities. 2008, 26(13/14), 542-551.

[7] Scofield, J. H. Do LEED-certified buildings save energy? Not really..., Energy and Buildings. 2009, 41(12), 1386-1390.

[8] Bordass, B., Cohen, R., Standeven, M., Leaman, A. Assessing building performance in use 3: energy performance of the Probe buildings. Building Research \& Information. 2001, 29(2), 114-128.

[9] Gunay, H. B., O'Brien, W., Beausoleil-Morrison, I. A critical review of observation studies, modeling, and simulation of adaptive occupant behaviors in offices. Building and Environment. 2013, 70, 31-47. 
655

656

657

658

659

660

661

662

663

664

665

666

667

668

669

670

671

672

673

674

675

676

677

678

679

680

681

682

683

684

685

686

687

688

[10] Cummings, N. G. Fostering Sustainable Behavior Through Design: A Study of the Social, Psychological, and Physical Influences of the Built Environment. Doctoral dissertation, University of Massachusetts Amherst. 2012.

[11] Haldi, F. A probabilistic model to predict building occupants' diversity towards their interactions with the building envelope. Proceedings of the International IBPSA Conference, Chambery, France. 2013, 1475-1482.

[12] Tetlow, R. M., van Dronkelaar, C., Beaman, C. P., Elmualim, A. A., Couling, K. Identifying behavioural predictors of small power electricity consumption in office buildings, Building and Environment. 2015, 92, 75-85.

[13] Schakib-Ekbatan, K., Çakıcı, F. Z., Schweiker, M., Wagner, A. Does the occupant behavior match the energy concept of the building?-Analysis of a German naturally ventilated office building, Building and Environment. 2015, 84, 142-150.

[14] Rea, M. S. Window blind occlusion: a pilot study, Building and Environment. 1984, 19, 133-137.

[15] Azar, E., Menassa, C.C. Agent-based modeling of occupants and their impact on energy use in commercial buildings. Journal of Computing in Civil Engineering. 2011, 26, 506-518. doi:10.1061/(ASCE)CP.1943-5487.0000158.

[16] Nisiforou, O., Poullis, S., Charalambides, A. Behaviour, attitudes and opinion of large enterprise employees with regard to their energy usage habits and adoption of energy saving measures, Energy and Buildings. 2012, 55, 299-311.

[17] Hong, T. Occupant behavior: impact on energy use of private offices, 1st Asia conference of International Building Performance Simulation Association. 2014. Shanghai, China.

[18] Dietz, T., Gardner, G. T., Gilligan, J., Stern, P. C., Vandenbergh, M. P. Household actions can provide a behavioral wedge to rapidly reduce US carbon emissions. Proceedings of the National Academy of Sciences of the United States of America. 2009, 106(44), 18452-18456.

[19] Gardner, G. T., Stern, P. C. The short list: The most effective actions US households can take to curb climate change, Environment: science and policy for sustainable development. 2008, 50(5), 12-25.

[20] Webber, C. A., Roberson, J. A., McWhinney, M. C., Brown, R. E., Pinckard, M. J., Busch, J. F. After-hours power status of office equipment in the USA. Energy. 2006, 31(14), 2823-2838.

[21] Masoso, O., Grobler, L. The dark side of occupants' behaviour on building energy use, Energy and Buildings. 2010, 42(2), 173-177.

[22] Morgan, C., de Dear, R. Weather, clothing and thermal adaptation to indoor climate. Climate Research. 2003, 24(3), 267-284.

[23] Parsons, K.C. The effects of gender, acclimation state, the opportunity to adjust clothing and physical disability on requirements for thermal comfort. Energy and Buildings. 2002, 34(6), 593-599. 
689

690

691

692

693

694

695

696

697

698

699

700

701

702

703

704

705

706

707

708

709

710

711

712

713

714

715

716

717

718

719

720

[24] Brohmann, B., Schmitt, K. Communication matters, knowledge collaboration \& learning for sustainable innovation. 14th European Roundtable on Sustainable Consumption and Production (ERSCP) conference and the 6th Environmental Management for Sustainable Universities (EMSU) conference. 2010. Delft, The Netherlands.

[25] Aggleton, P. Behavior change communication strategies. AIDS Education and Prevention : Official Publication of the International Society for AIDS Education. 1997, 9(2), 111-123.

[26] Bickmore, T. W., Sidner, C. Towards Plan-based health behavior change counseling systems. AAAI Spring Symposium: Argumentation for Consumers of Healthcare. 2006, 14-18.

[27] Bickmore, T., Gruber, A., Picard, R. Establishing the computer-patient working alliance in automated health behavior change interventions. Patient education and counseling. 2005, 59(1), 21-30.

[28] Mowen, J.C., Cialdini, R. B. On implementing the door-in-the-face compliance technique in a business context. Journal of Marketing Research. 1980, 253-258.

[29] Bonte, M., Thellier, F., Lartigue, B. Impact of occupant's actions on energy building performance and thermal sensation. Energy and Buildings. 2014, 76, 219-227.

[30] Yun, G. Y., Kim, H., Kim, J. T. Effects of occupancy and lighting use patterns on lighting energy consumption. Energy and Buildings. 2012, 46, 152-158.

[31] Parys, W., Saelens, D., Hens, H. Impact of occupant behavior on lighting energy use. Proceedings of Building Simulation. 2009, 1143-1150.

[32] Pallak, M. S., Cummings, W. Commitment and voluntary energy conservation. Personality and Social Psychology Bulletin. 1976, 2(1), 27-30.

[33] Shippee, G., Gregory, W. L. Public commitment and energy conservation. American Journal of Community Psychology. 1982, 10(1), 81-93.

[34] Becker, L. J. Joint effect of feedback and goal setting on performance: A field study of residential energy conservation. Journal of applied psychology. 1978, 63(4), 428.

[35] Van Houwelingen, J. H., Van Raaij, W. F. The effect of goal-setting and daily electronic feedback on in-home energy use. Journal of consumer research. 1989, 98-105.

[36] Midden, C. J., Meter, J.F., Weenig, M.H., Zieverink, H.J. Using feedback, reinforcement and information to reduce energy consumption in households: A field-experiment. Journal of Economic Psychology. 1983, 3(1), 65-86.

[37] McMakin, A. H., Malone, E.L ., Lundgren, R. E. Motivating residents to conserve energy without financial incentives. Environment and Behavior. 2002, 34(6), 848-863. 
[38] Siero, F. W., Bakker, A. B., Dekker, G. B., Van Den Burg, T.C. M. Changing organizational energy consumption behaviour through comparative feedback. Journal of Environmental Psychology. 1996, 16, 235-246.

[39] Darby, S. \{\{1436 Siero, Frans W 1996\}\}The effectiveness of feedback on energy consumption. A Review for DEFRA of the Literature on Metering, Billing and direct Displays. 2006..

726

727

[40] Yang, J. C., Chien, K. H., Liu, T.C. A digital game-based learning system for energy education: An energy conservation PET. Turkish Online Journal of Educational Technology-TOJET. 2012, 11(2), 27-37.

[41] Gustafsson, A., Katzeff, C., Bang, M. Evaluation of a pervasive game for domestic energy engagement among teenagers. Computers in Entertainment (CIE). 2009, 7(4), 54:1-54:19.

[42] Van de Velde, L., Verbeke, W., Popp, M., Van Huylenbroeck, G. The importance of message framing for providing information about sustainability and environmental aspects of energy. Energy Policy. 2010, 38(0), 5541-5549.

[43] Winett, R. A., Leckliter, I. N., Chinn, D. E., Stahl, B., Love,S . Q. Effects of television modeling on residential energy conservation. Journal of applied behavior analysis. 1985, 18(1), 33-44.

[44] Hutton, R. B., McNeill, D. L. The value of incentives in stimulating energy conservation. Journal of Consumer Research. 1981, 291-298.

[45] Stern, P. C., Aronson, E., Darley, J. M., Hill , D. H., Hirst, E., Kempton, W., Wilbanks, T. J. The effectiveness of incentives for residential energy conservation. Evaluation review. 1986, 10(2), 147-176.

[46] Abrahamse, W., Steg, L., Vlek, C., Rothengatter, T. A review of intervention studies aimed at household energy conservation. Journal of Environmental Psychology. 2005, 25(3), 273-291.

[47] Peschiera, G., Taylor, J. E. The impact of peer network position on electricity consumption in building occupant networks utilizing energy feedback systems, Energy and Buildings. 2012, 49, 584-590.

[48] Carrico, A. R., Riemer, M. Motivating energy conservation in the workplace: An evaluation of the use of group-level feedback and peer education, Journal of Environmental Psychology. 2011, 31(1),1-13.

[49] Cialdini, R. B. Crafting normative messages to protect the environment. Current directions in psychological science. 2003, 12(4), 105-109.

[50] Cooter, R. D., Feldman, M., Feldman, Y. The misperception of norms: The psychology of bias and the economics of equilibrium. Review of Law \& Economics. 2008, 4(3), 889-911.

[51] Goldstein, N. J., Cialdini, R. B., Griskevicius, V. A room with a viewpoint: Using social norms to motivate environmental conservation in hotels. Journal of consumer Research. 2008, 35(3), 472-482.

[52] Nolan, J. M., Schultz, P. W., Cialdini, R. B., Goldstein, N. J., Griskevicius, V. Normative social influence is underdetected. Personality \& social psychology bulletin. 2008, 34(7), 913-923.

[53] Zhang, T., Siebers, P., Aickelin, U. Modelling electricity consumption in office buildings: An agent based approach. Energy and Buildings. 2011, 43(10), 2882-2892. 
[54] Allcott ,H. Social norms and energy conservation. Journal of Public Economics. 2011, 95(9), 10821095.

[55] Schultz, P.W., Nolan, J. M., Cialdini, R. B., Goldstein, N. J., Griskevicius, V. The constructive, destructive, and reconstructive power of social norms. Psychological science. 2007, 18(5), 429-434.

[56] Ayres, I., Raseman, S., Shih, A. Evidence from two large field experiments that peer comparison feedback can reduce residential energy usage. Journal of Law, Economics, and Organization. 2013, 29, 992-1022

[57] Oliver, P., Marwell, G., Teixeira, R. A theory of the critical mass. I. Interdependence, group heterogeneity, and the production of collective action. American journal of Sociology. 1985,522-556.

[58] Axsen, J., Kurani, K. S. Social influence, consumer behavior, and low-carbon energy transitions. Annual Review of Environment and Resources. 2012, 37, 311-340.

[59] Freedman, J. L., Fraser, S. C. Compliance without pressure: the foot-in-the-door technique. Journal of personality and social psychology. 1966, 4(2), 195.

[60] Wheeless, L. R., Barraclough, R., Stewart, R., Bostrom, R. Compliance-gaining and power in persuasion, Communication yearbook. 1983, 7,105-145.

[61] Scott, C. A. Modifying socially-conscious behavior: The foot-in-the-door technique. Journal of Consumer Research. 1977, 156-164.

[62] Reingen, P. H. On inducing compliance with requests. Journal of Consumer Research. 1978, 96-102.

[63] Guéguen, N. Foot-in-the-door technique and computer-mediated communication. Computers in Human Behavior. 2002, 18(1), 11-15.

[64] Gueguen, N., Marchand, M., Pascual, A., Lourel,M. Foot-in-the-door technique using a courtship request: a field experiment 1. Psychological reports. 2008, 103(2), 529-534.

[65] Guéguen,N., Jacob,C., Fund-raising on the web: the effect of an electronic foot-in-the-door on donation, Cyber Psychology \& Behavior. 2001, 4,705-709.

[66] Girandola, F. Sequential requests and organ donation. The Journal of social psychology. 2002, 142(2), 171-178.

[67] Grassini, A., Pascual, A., Guéguen, N. The effect of the foot-in-the-door technique on sales in a computer-mediated field setting. Communication Research Reports. 2013, 30(1), 63-7.

[68] Guadagno, R. E., Liberman, C. Social influence online: The six principles in action. Casing persuasive communication. Kendall Hunt. 2013. Dubuque, IA.

[69] Gouldner, A.W. The norm of reciprocity: A preliminary statement. American Sociological Review. 1960, 161-178. 
[70] Conner, A. E. A general framework for modifying health-relevant behavior: Reducing undergraduate binge drinking by appealing to commitment and reciprocity. Doctoral dissertation, Kansas State University. 2005.

[71] Regan, D. T. Effects of a favor and liking on compliance. Journal of experimental social psychology. $1971,7(6), 627-639$.

[72] Whatley, M. A., Webster, J. M., Smith, R. H., Rhodes, A. The effect of a favor on public and private compliance: How internalized is the norm of reciprocity? Basic and Applied Social Psychology. 1999, 21(3), 251-259.

[73] Takeuchi, Y., Katagiri, Y., Nass, C. I., Fogg, B. Social response and cultural dependency in humancomputer interaction. Proceedings of PRICAI. 1998, 114-123.

[74] Nass, C., Moon, Y. Machines and mindlessness: Social responses to computers. Journal of Social Issues. 2000, 56(1), 81-103.

[75] Moon, Y. Intimate exchanges: Using computers to elicit self-disclosure from consumers. Journal of consumer research. 2000, 26(4), 323-339.

[76] Fogg, B., Nass, C. How users reciprocate to computers: an experiment that demonstrates behavior change. CHI'97 extended abstracts on Human factors in computing systems. 1997, 331-332.

[77] Burger, J. M., Sanchez, J., Imberi, J. E., Grande, L. R. The norm of reciprocity as an internalized social norm: Returning favors even when no one finds out. Social Influence. 2009, 4(1), 11-17.

[78] Gaudeul, A., Peroni, C. Reciprocal attention and norm of reciprocity in blogging networks. Jena economic research papers. 2010, 20.

[79] Sapci, O., Considine,T. The link between environmental attitudes and energy consumption behavior. Journal of Behavioral and Experimental Economics. 2014, 52, 29-34.

[80] Shen, M., Cui, Q., Fu, L. Personality traits and energy conservation. Energy Policy. 2015, 85, 322334.

[81] Nass, C., Gong, L. Speech interfaces from an evolutionary perspective. Communications of the ACM. 2000, 43(9), 36-43.

[82] Rickenberg, R., Reeves, B. The effects of animated characters on anxiety, task performance, and evaluations of user interfaces. Proceedings of the SIGCHI conference on Human factors in computing systems. 2000, 49-56.

[83] Psotka, J. Immersive training systems: Virtual reality and education and training. Instructional science. 1995, 23(5-6), 405-431.

[84] Rizzo, A., Buckwalter, J. G., van der Zaag, C., Neumann,U., Thiébaux, M., Chua, C., van Rooyen, A., Humphrey, L., Larson, P. Virtual environment applications in clinical neuropsychology. Virtual Reality, 2000. Proceedings .IEEE. 2000, 63-70. 
[85] Mujber, T. S., Szecsi, T., Hashmi, M. S. Virtual reality applications in manufacturing process simulation, Journal of Materials Processing Technology. 2004, 155, 1834-1838.

[86] Blascovich, J., Loomis, J., Beall, A. C., Swinth, K. R., Hoyt, C. L., Bailenson, J. N. Immersive virtual environment technology as a methodological tool for social psychology. Psychological Inquiry. 2002, 13(20), 103-124.

[87] Khashe, S., Heydarian, A., Gerber, D., Becerik-Gerber, B., Hayes, T., Wood, W. Influence of LEED branding on building occupants' pro-environmental behavior. Building and Environment. 2015, 94, 477488.

[88] Bombari, D., Mast, M. S., Canadas, E., Bachmann, M. Studying social interactions through immersive virtual environment technology: virtues, pitfalls, and future challenges. Frontiers in psychology. 2015, 6, 869 .

[89] Yee, N., Bailenson, J. N., Rickertsen, K. A meta-analysis of the impact of the inclusion and realism of human-like faces on user experiences in interfaces.Proceedings of the SIGCHI conference on Human factors in computing systems, 2007, 1-10

[90] Ahn, S.J.G., Fox, J., Dale, K. R., Avant, J. A. Framing Virtual Experiences Effects on Environmental Efficacy and Behavior Over Time. Communication Research. 2014. 42(6), 839-863. doi: $10.1177 / 0093650214534973$.

[91] Heydarian, A., Carneiro, J. P., Gerber, D., Becerik-Gerber, B., Hayes, T., Wood, W. Immersive virtual environments versus physical built environments: A benchmarking study for building design and user-built environment explorations. Automation in Construction. 2015, 54, 116-126.

[92] Rhoads, K.V., Cialdini, R. B. The business of influence: Principles that lead to success in commercial settings. The persuasion handbook: Developments in theory and practice. 2002, 513-542.

[93] Malhotra, D., Bazerman, M. H. Psychological influence in negotiation: An introduction long overdue. Journal of Management. 2008, 34(3), 509-531.

[94] John, O. P., Srivastava, S. The Big Five trait taxonomy: History, measurement, and theoretical perspectives. Handbook of personality: Theory and research. 1999, 2, 102-138.

[95] Ishaswini., Datta, S. K. Pro-environmental concern influencing green buying: A study on Indian consumers. International Journal of Business and management. 2011, 6(6), 124-133.

[96] Kahn, J. Reporting statistics in APA style. Last accessed: November 2015, Available at: http://my.ilstu.edu/ \%20jhkahn/apastats.html

[97] Karjalainen, S., Consumer preferences for feedback on household electricity consumption. Energy and Buildings. 2011, 43(2), 458-467.

[98] Jain, R. K., Taylor, J. E., Peschiera, G. Assessing eco-feedback interface usage and design to drive energy efficiency in buildings. Energy and Buildings. 2012, 48, 8-17. 
855

856

857

858

859

860

861

862

863

864

865

866

867

868

869

870

871

872

873

874

875

[99] Maan, S., Merkus, B., Ham, J., Midden, C. Making it not too obvious: the effect of ambient light feedback on space heating energy consumption. Energy Efficiency. 2011, 4(2), 175-183.

[100] Chen, H., Lin, C., Hsieh, S., Chao, H., Chen, C., Shiu, R., Ye, S., Deng, Y. Persuasive feedback model for inducing energy conservation behaviors of building users based on interaction with a virtual object. Energy and Buildings. 2012, 45, 106-115.

[101] Umaki, T. M., Umaki, M.R., Cobb, C. M. The psychology of patient compliance: a focused review of the literature. Journal of periodontology. 2012, 83(4), 395-400.

[102] McCrae, R. R., John, O. P. An introduction to the five-factor model and its applications. Personality: critical concepts in psychology. 1992, 175-215.

[103] Emilsson, M., Berndtsson, I., Lotvall, J., Millqvist, E., Lundgren, J., Johansson, A., Brink, E. The influence of personality traits and beliefs about medicines on adherence to asthma treatment. Primary care respiratory journal : journal of the General Practice Airways Group. 2011, 20(2), 141-147.

[104] Hilliard, R. C., Brewer, B. W., Cornelius, A. E., Van Raalte, J. L. Big Five Personality Characteristics and Adherence to Clinic-Based Rehabilitation Activities After ACL Surgery: A Prospective Analysis. The open rehabilitation journal. 2014, 7, 1-5.

[105] Milfont, T. L., Sibley, C. G. The big five personality traits and environmental engagement: Associations at the individual and societal level. Journal of Environmental Psychology. 2012, 32(2), 187 195.

[106] Hampson, S .E. Personality processes: mechanisms by which personality traits "get outside the skin". Annual Review of Psychology. 2012, 63, 315-339. 